\title{
Mechanism of promoted dipeptide formation on hydroxyapatite crystal surfaces
}

\author{
WU Jia, ZHANG ZhiShen, YU XinWei, PAN HaiHua, JIANG WenGe, XU XuRong \& \\ TANG RuiKang ${ }^{*}$
}

Department of Chemistry and Center for Biomaterials and Biopathways, Zhejiang University, Hangzhou 310027, China

Accepted March 29, 2010; accepted August 31, 2010; published online January 12, 2011

\begin{abstract}
The formation of dipeptides from amino acids can be driven by hydroxyapatite at a relatively low temperature in air. For example, the formation of $(\mathrm{Ala})_{2}$ from Ala is induced on hydroxyapatite at $110^{\circ} \mathrm{C}$ with considerable yield. Typically, condensing agents, high temperatures $\left(>250^{\circ} \mathrm{C}\right)$ or high pressures $(>25 \mathrm{MPa})$ are required to drive the condensation of amino acids. Similar effects are observed in the condensation of Gly, Glu and Asp. Experiments demonstrate that hydroxyapatite is an effective inorganic catalytic agent, reducing the activation barrier for the formation of dipeptides by more than $50 \%$. HAP promotes condensation by adsorbing amino acid monomers in an organized manner, which decreases the distance between amino and carboxyl groups on neighboring molecules and extends the contact time of the reaction groups. This work provides a chemical understanding of the primitive condensation of amino acids and reveals a mechanism for enhancement of mineral catalysts. It is important that the conditions used for hydroxyapatite-assisted dipeptide formation are not harsh and can be readily achieved, revealing a possible mechanism for the chemical evolution of biomolecules over geologic ages.
\end{abstract}

condensation reaction, dipeptide, hydroxyapatite, amino acid, catalysis

Citation: Wu J, Zhang Z S, Yu X W, et al. Mechanism of promoted dipeptide formation on hydroxyapatite crystal surfaces. Chinese Sci Bull, 2011, 56: 633-639 doi: $10.1007 / \mathrm{s} 11434-010-4314-\mathrm{x}$

The initiation of polymerization of amino acids is a vital step in the primitive formation of proteins and this procedure is irreplaceable in the chemical evolution of life precursors [1-4]. However, the condensation reaction involving the elimination of $\mathrm{H}_{2} \mathrm{O}$ molecules between amino acids to link them together is not favored energetically or dynamically $[5,6]$. It is generally believed that inorganic minerals have an important role in the primitive evolution of biomolecules because they were present in large amounts in the prebiotic earth crust after the formation of the hydrosphere [7]. It has been suggested that clays such as montmorillonite and kaolin facilitate the synthesis of organic molecules [8-11]. These clays can enhance the conversion of amino acid amides into polypeptides; however, the mechanism is still unknown. Polycondensation of amino acids has also

*Corresponding author (email: rtang@zju.edu.cn) been observed on silica and alumina surfaces but its efficiency is poor [12]. It should be noted that condensing agents (e.g. carbonyl diimidazole [13]), high temperature $\left(>250^{\circ} \mathrm{C}\right)$ and high pressure $(>25 \mathrm{MPa})$ are still frequently used to promote amide formation [13,14]. However, these models cannot provide a better understanding of the primitive formation of dipeptides because they require harsh conditions. It has been noted that calcium phosphate minerals are widely distributed on our planet. Among them, hydroxyapatite (HAP, $\left.\mathrm{Ca}_{10}\left(\mathrm{PO}_{4}\right)_{6}(\mathrm{OH})_{2}\right)$ is the most thermodynamically stable $[15,16]$. Unlike other inorganic compounds, HAP is also an important biomineral with specific affinity for amino acids, peptides and proteins [17-22]. Therefore, it is reasonable to suggest that HAP may accumulate biomolecules to promote their chemical evolution. Here, we show that amino acids can be linked on an HAP surface at a relatively low temperature $\left(110^{\circ} \mathrm{C}\right)$ in air. The 
catalytic effect originates from the organized adsorption of amino acid monomers on the HAP surface, which significantly reduces the distance between intermolecular amino and carboxyl groups as well as increasing their contact time. From the viewpoint of cybernetic chemistry [23], these features can greatly reduce the activation barrier to facilitate the polymerization of amino acids. This study provides physicochemical insight into the mechanism of mineralbased catalysis in the primitive evolution of biomolecules under relatively mild conditions in air.

The hydration-dehydration process in the hydrothermal conversion of amino acid amides into polypeptides in a marine environment is widely accepted as an important pathway in the formation of life precursors [14,24-26]. Evaporation of a solution of amino acids to dryness and subsequent heating of the dried molecules has often been used as an experimental model in laboratories [27-29]. In the current study, a mixture of amino acid solution and HAP crystals was thermally treated to simulate this natural process.

\section{Experiments and methods}

\subsection{Materials}

The four typical amino acids used in this study, $L$ - $\alpha$-alanine (Ala), glycine (Gly), glutamic acid (Glu) and aspartic acid (Asp) were purchased from Sinopharm Chemical Reagent Co., Ltd. Dialanine (Ala) $)_{2}$ and diglycine $(\text { Gly })_{2}$ were purchased from Sigma. Diketopiperazine (DKP) was purchased from Acros Organics. HAP crystals were synthesized as follows. Distilled water $(500 \mathrm{~mL})$ and $\mathrm{CaCl}_{2}(0.5 \mathrm{~mol} / \mathrm{L}$, $250 \mathrm{~mL}$ ) were mixed in a reaction vessel and the $\mathrm{pH}$ was adjusted to 9.5 using ammonia. A solution of $\left(\mathrm{NH}_{4}\right)_{2} \mathrm{HPO}_{4}$ $(0.3 \mathrm{~mol} / \mathrm{L}, 250 \mathrm{~mL})$ was then added drop-wise. The $\mathrm{pH}$ was maintained at 9.5 by slowly adding ammonia. The precipitated HAP solids were collected by centrifugation at $5000 \mathrm{r} / \mathrm{min}$, and then washed extensively with distilled water.

\subsection{Condensation and characterization}

Condensation of monomeric amino acids on HAP was performed by heating a mixture of HAP (400 mg) and a solution of amino acids $(2 \mathrm{~mL}, 1 \mathrm{~mol} / \mathrm{L})$ in a glass beaker at $110-190^{\circ} \mathrm{C}$ in air for $10 \mathrm{~h}$. In the control experiment, only a solution of amino acids was added to the beaker. After the thermal treatment, distilled water $(10 \mathrm{~mL})$ was added into the beaker and then left for $24 \mathrm{~h}$ to dissolve the adsorbed compounds from HAP. After centrifugation at $12000 \mathrm{r} / \mathrm{min}$ and filtration through a $0.22-\mu \mathrm{m}$ Millipore membrane, the composition of filtrate was examined by high-performance liquid chromatography (HPLC, Agilent 1100, Agilent Technologies, Paulo Alto, CA, USA) with a reverse-phase column (Zorbax Eclipse XDB-C18, Hewlett-Packard, Newport, DE, USA). The mobile phase consisted of $\mathrm{KH}_{2} \mathrm{PO}_{4}$
$(50 \mathrm{mmol} / \mathrm{L})$ and $\mathrm{C}_{6} \mathrm{H}_{13} \mathrm{SO}_{3} \mathrm{Na}(7.2 \mathrm{mmol} / \mathrm{L})$, with the $\mathrm{pH}$ adjusted to 2.5 by $\mathrm{H}_{3} \mathrm{PO}_{4}$. The flow rate of the mobile phase was $1 \mathrm{~mL} / \mathrm{min}$. The compounds were analyzed at $195 \mathrm{~nm}$ with a UV detector. The reaction yields were determined as the percentage of reactant converted to the reaction product. The products were identified by liquid chromatography/mass spectrometry LC-MS (Agilent 1100 LC/MSD SL, Agilent Technologies, Paulo Alto, CA, USA).

\subsection{Computer simulation}

The Hauptmann apatite model [30] was used for the simulation, and the experimental crystal parameters and infrared spectra of HAP were accurately reproduced by the simulation. An HAP (010) interface was created by splitting the crystal structure and inserting a layer of water with a thickness of $3 \mathrm{~nm}$ and a density of $1000 \mathrm{~kg} / \mathrm{m}^{3}$ between the separated crystal surfaces. Simple point charge (SPC) force fields, which are widely used in the modeling of large aqueous biological systems, were applied for water. Optimized potentials for liquid simulations for all atom (OPLSAA) force fields, which are commonly used in biological systems, were applied for the amino acids. Molecular dynamic (MD) simulations were performed using Gromacs 3.3 [31,32] software Periodic boundary conditions were applied in all directions. Particle mesh Ewald (PME) summation was applied for the treatment of the long-range Columbic interactions, with a cutoff distance of $1.3 \mathrm{~nm}$. Simulations were performed using the NpT ensemble [33]. Anisotropic Berendsen pressure coupling was applied allowing cell shape variation so as not to impose artificial symmetry restrictions. A time step of 2 fs was found to be appropriate. Initial velocities according to the Maxwell distribution at the desired temperature were used as the starting configuration. To ensure thermodynamic equilibrium, the data from the first $1 \mathrm{~ns}$ of the NpT run was abandoned, and the remaining data was used for radial distribution function analysis.

\section{Results and discussion}

The specimens after thermal treatment were characterized by comparing the HPLC retention times of the products, which were indentified by LC-MS, with those of standard reagents (Figure 1(a)). In the control experiments, the condensation of Ala did not occur in the temperature range between 110 and $190^{\circ} \mathrm{C}$, indicating an inert nature of Ala in spontaneous condensation. However, when HAP solids were added, the amide reaction of Ala could be initiated. Some new peaks were found in the HPLC profiles of the reaction products when the temperature was above $110^{\circ} \mathrm{C}$ (Figure 1(b)). It was confirmed by LC-MS that DKP (143.1 $\left.[\mathrm{M}+\mathrm{H}]^{+}, 158.9\left[\mathrm{M}+\mathrm{NH}_{4}\right]^{+}, 165.1[\mathrm{M}+\mathrm{Na}]^{+}\right)$and $(\mathrm{Ala})_{2}$ 

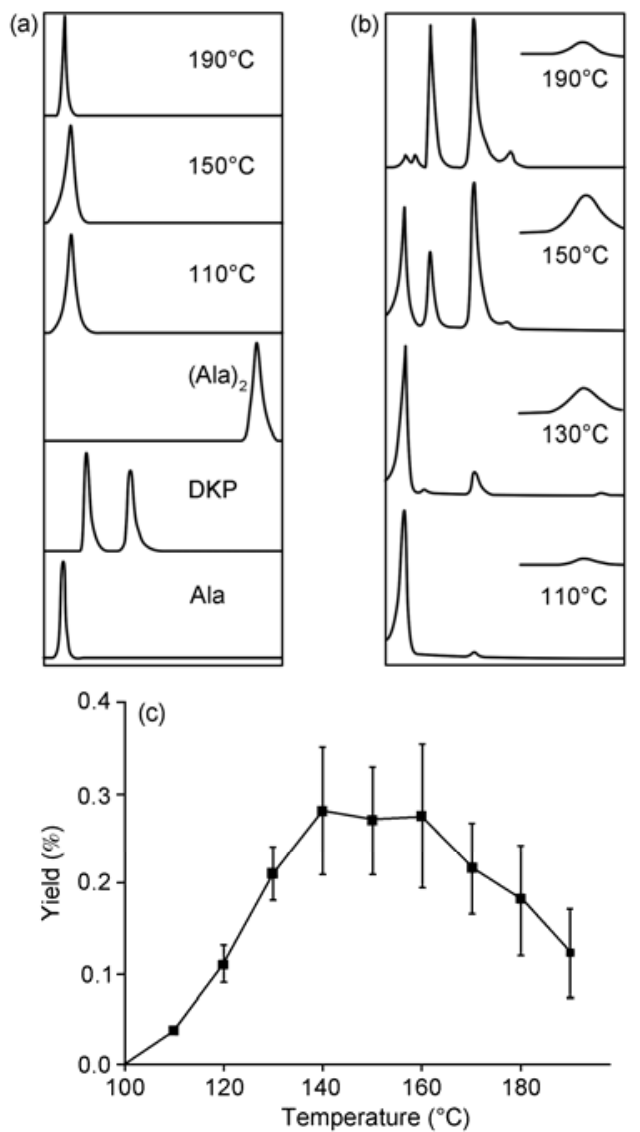

Figure 1 (a) HPLC of authentic reagent (Ala) and products (Ala $)_{2}$ and DKP) in the absence of HAP. (b) HPLC of the products in the presence of HAP; the (Ala $)_{2}$ peaks have been enlarged. (c) Yields of (Ala) $)_{2}$ from 10-hour cycles at different temperatures.

$\left(161.1[\mathrm{M}+\mathrm{H}]^{+}, 183.1[\mathrm{M}+\mathrm{Na}]^{+}\right)$were produced. At a temperature of $110^{\circ} \mathrm{C}$, the estimated yield of (Ala $)_{2}$ was $\sim 0.03 \%$ after $10 \mathrm{~h}$. The reaction yield increased with temperature and the highest yield, $\sim 0.28 \%$, was achieved at $140-190^{\circ} \mathrm{C}$ (Figure 1(c)). It should be emphasized that only a 10-h cycle was applied in this experiment; the yield reached 6\%-10\% when the reaction time was extended to 1 month compared with the small yield without HAP. Clearly, HAP readily catalyzed the formation of (Ala) $)_{2}$. The experimental conditions used were not harsh, so it is realistic that they could be provided by the earth.

It should be noted that the formation of DKP frequently dominated the condensation reaction. This phenomenon can be attributed to the intramolecular condensation of Ala [34], which proceeded readily because of the short distance between the amino and carboxyl groups of a single Ala molecule. Besides, the stereochemical feasibility of Ala made the intramolecular condensation much more readily $[35,36]$. It has been reported that the activation energy for the conversion of (Ala $)_{2}$ to DKP is significantly lower than that for the formation of (Ala $)_{2}$ from two Ala molecules, and the formation of DKP is preferred in most condensation reactions especially at relatively high temperature [37]. Accordingly, in our experiments the yield of (Ala) $)_{2}$ decreased remarkably when temperature was $>150^{\circ} \mathrm{C}$. This result also reveals the importance of a lower temperature in the generation of dipeptides under thermal conditions.

Similar results were obtained for the condensation of Gly (Figure 2). In the absence of HAP, the formation of diglycine was not detected even when the reaction temperature was increased to $130^{\circ} \mathrm{C}$. However, a signal consistent with $(\mathrm{Gly})_{2}$ was found in the HPLC profiles of products when the temperature was only $100^{\circ} \mathrm{C}$ in the presence of HAP. The yield of $(\mathrm{Gly})_{2}$ increased significantly as the temperature increases. The intramolecular condensation side reaction was not significant when temperature was lower than $130^{\circ} \mathrm{C}$. However, performing the reaction at a higher temperature led to significant amounts of intramolecular condensation.

The effect of HAP in promoting dipeptide formation was further confirmed using other amino acids such as Glu and Asp (Figure 3). In the control experiments performed without HAP, there was no product signal in the HPLC profiles when the reaction temperature was $130^{\circ} \mathrm{C}$. However, the formation of $(\mathrm{Glu})_{2}$ and $(\mathrm{Asp})_{2}$ with estimated yields of around $0.06 \%$ and $0.1 \%$, respectively, were observed at $130^{\circ} \mathrm{C}$ when HAP was added to the reaction mixture. The results clearly show that HAP promotes the thermal condensation of Glu and Asp. It is expected that the general trend found for the above-mentioned amino acids will also hold for the formation of other dipeptides.

It was noticed that the yield of (Ala $)_{2}$ was negligible at a low temperature $\left(<110^{\circ} \mathrm{C}\right)$ and that the formation of DKP dominated the reaction at a high temperature $\left(>150^{\circ} \mathrm{C}\right)$.
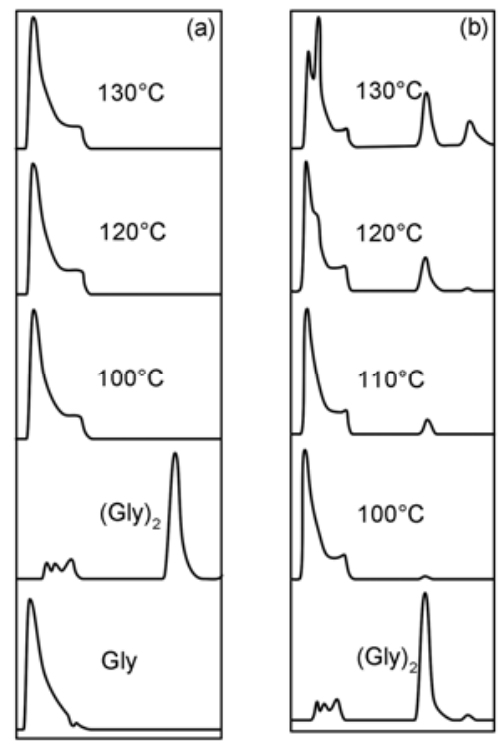

Figure 2 (a) HPLC of the products from condensation of Gly in the absence of HAP. (b) HPLC of the products from condensation of Gly in the presence of HAP. 


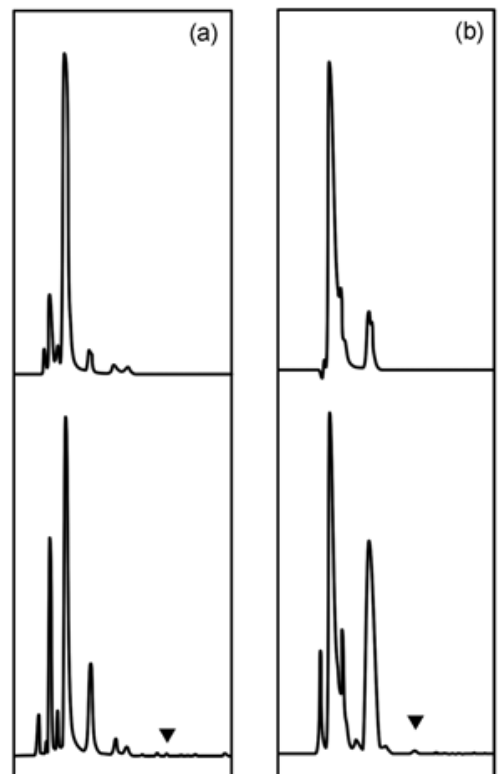

Figure 3 (a) Condensation of Glu; (b) condensation of Asp. The upper and lower curves show the products from reaction at $130^{\circ} \mathrm{C}$ in the absence and presence of HAP, respectively. The dipeptide signals are indicated by an arrow.

Therefore, a suitable temperature range was essential for the formation of $(\mathrm{Ala})_{2}$ in air. Because of the relatively fast generation of $(\mathrm{Ala})_{2}$ on the HAP surface, a 10 -h reaction time was sufficient for the analysis. In kinetic studies, approximately linear relationships between the (Ala) $)_{2}$ concentration and reaction time, $t$, were found between temperatures of 110 and $140^{\circ} \mathrm{C}$ (Figure 4(a)), indicating a pseudozero order reaction. HPLC analysis showed that the change in the amount of Ala during the reaction was not remarkable (less than $5 \%$ ) after $10 \mathrm{~h}$, even at $140^{\circ} \mathrm{C}$. Thus, the reaction rate could be estimated directly from the slope of the plot of the concentration of (Ala) $)_{2}$ against $t$. At $110^{\circ} \mathrm{C}$, (Ala) $)_{2}$ was generated at a rate of $3.7 \times 10^{-8} \mathrm{~mol} / \mathrm{h}$, which is defined as a relative rate constant, $k$, of 1 . The $k$ values at 120,130 and $140^{\circ} \mathrm{C}$ were about 3.0, 5.8 and 7.5, respectively. A plot of $\ln k$ against $1 / T$ ( $T$ is the absolute temperature) gave a straight line (Figure 4(b)) and the behavior of the data was expressed mathematically by the Arrhenius equation,

$$
\ln k=\ln A-\frac{E_{\mathrm{a}}}{R T},
$$

where $A$ and $R$ are the frequency factor and gas constant, respectively. The activation energy, $E_{\mathrm{a}}$, was obtained from the slope of the line, $-E_{\mathrm{a}} / R$. It was calculated that the $E_{\mathrm{a}}$ for $(\text { Ala })_{2}$ formation on HAP was just $\sim 89 \mathrm{~kJ} / \mathrm{mol}$. The kinetic behavior of $(\mathrm{Gly})_{2}$ generation on the HAP mineral surface was also examined. Analogous to that in the Ala system, a pseudo-zero order reaction was obtained for a reaction time of $10 \mathrm{~h}$. At $100^{\circ} \mathrm{C},(\mathrm{Gly})_{2}$ was produced at a rate of $1.27 \times$ $10^{-7} \mathrm{~mol} / \mathrm{h}$, which was defined as a relative rate constant, $k$, of 1 . The $k$ values at 110,120 and $130^{\circ} \mathrm{C}$ were about 2.91 , 4.74 and 7.09, respectively (Figure 5). Thus, a value of $E_{\mathrm{a}}$ of $80 \mathrm{~kJ} / \mathrm{mol}$ for $(\mathrm{Gly})_{2}$ formation on HAP, was also estimated using the Arrhenius equation. Previous studies have reported that Gly is the amino acid with the greatest propensity to form dipeptides [38]. The reported the $E_{\mathrm{a}}$ for amide bond formation between Gly molecules was $209 \mathrm{~kJ} / \mathrm{mol}$ [39], which was more than 2.5 times larger than that found in the presence of HAP. Furthermore, the role of silica has been already highlighted in previous studies on mineral-assisted condensation. In comparison, it was reported that the adsorption of Gly on silica reduced the $E_{\mathrm{a}}$ by only $10 \%$ [40]. In our experiment, HAP decreased the $E_{\mathrm{a}}$ of Gly condensation by more than $60 \%$. The $E_{\text {a }}$ for the dimerization of Ala is greater than that of Gly. Even under harsh hydrothermal conditions (temperature $>120^{\circ} \mathrm{C}$ and pressure of $2 \mathrm{MPa}$ ), the reported $E_{\mathrm{a}}$ for the formation of (Ala) $)_{2}$ was $114 \mathrm{~kJ} / \mathrm{mol}$ [37]. In contrast HAP reduced the $E_{\mathrm{a}}$ to $\sim 89 \mathrm{~kJ} / \mathrm{mol}$. Clearly, the catalytic effect of HAP on the condensation of amino acids is significant. Our results suggest that it is the most effective inorganic catalytic agent for the formation of dipeptides found to date.

The mechanism for how HAP crystals promote the formation of $(\mathrm{Ala})_{2}$ is not yet understood. Although the en
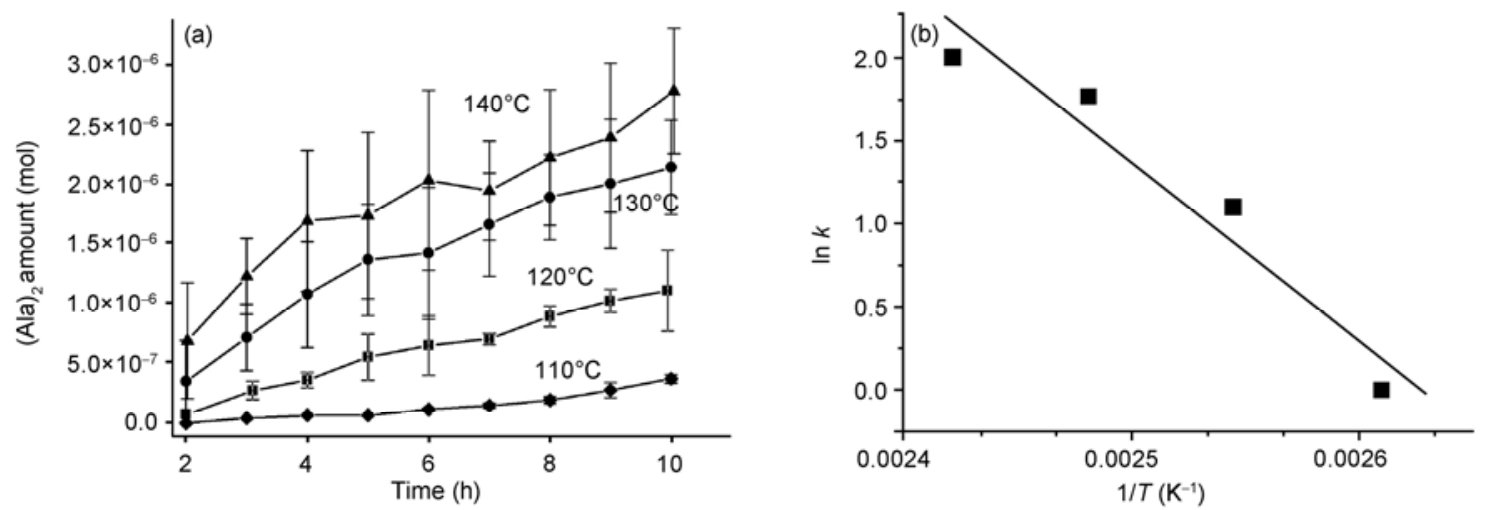

Figure 4 (a) Formation of (Ala $)_{2}$ as a function of experimental time. (b) Plot of $\ln k$ against $1 / T$. 


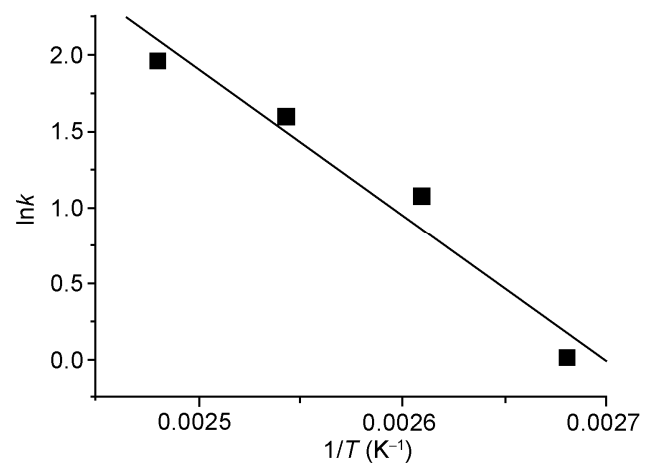

Figure 5 Plot of $\ln k$ against $1 / T$ for generation of (Gly $)_{2}$ on HAP.

hancement induced by various inorganic minerals on the formation of dipeptides and polypeptides have been well reported, the mechanism for this effect is still unclear. It is important to understand the behavior of amino acid molecules on the mineral surface. Sophisticated computer simulation can provide a powerful tool to investigate this behavior. The adsorption of different amino acids on HAP $\{100\}$ facets (the largest habit surfaces in HAP crystals) were studied at the atomic level. Unlike on other minerals, the adsorption of Ala on HAP was strong and well-organized [23]. The simulation results showed that each Ala molecule had a certain adsorption site (Figure 6(a)). The distance between an $\mathrm{H}$ atom of the amino group in an Ala and an $\mathrm{O}$ atom of the carboxyl group from the neighbouring Ala molecule was $0.169 \mathrm{~nm}$ (Figure 6(b)). The radial distribution function (Rdf) confirmed that the maximum distribution of an $\mathrm{H}$ atom in the amino group was $0.169 \mathrm{~nm}$ away from an $\mathrm{O}$ atom in the carboxyl group of the neighbouring molecule (Figure 6(c)). Thus, the formation of a hydrogen bond was induced. The intermolecular distance between $\mathrm{N}$ and $\mathrm{C}$ was fixed at around $0.330-0.370 \mathrm{~nm}$ on the HAP surface (Figure 6(d)). The same result was obtained at the Gly-HAP adsorption interface (Figure 7). The distance between an $\mathrm{H}$ atom of the amino group in a Gly molecule and an $\mathrm{O}$ atom in the carboxyl group of the neighbouring Gly was $0.172 \mathrm{~nm}$, and the intermolecular distance between $\mathrm{N}$ and $\mathrm{C}$ was fixed at $0.365 \mathrm{~nm}$ on the HAP surface. Because adsorption restricts the movement of Ala and Gly molecules on HAP, the contact time between the two reaction groups was extended. In our computer simulation, the configurations of the neighbouring amino acid monomers remained unchanged over the whole simulation period ( $>2 \mathrm{~ns}$ ) after adsorption. The extended contact time is another important factor in increasing the reaction between amino acids.

\section{Conclusions}

In this study, it was shown that the condensation of amino acids to dipeptides is greatly promoted by mineral HAP. Amino acid molecules are adsorbed into an organized pattern on HAP, which places neighbouring molecules in closer proximity for condensation. Using HAP to catalyze the (a)
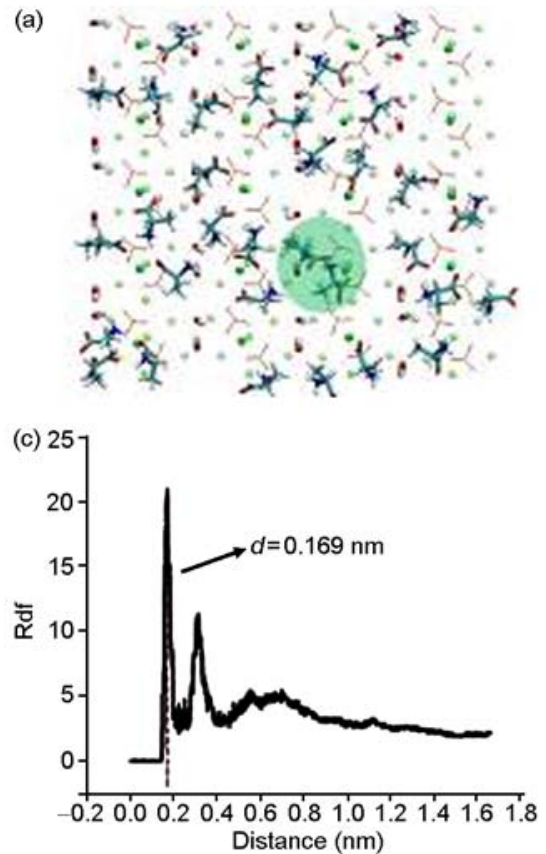

(b)
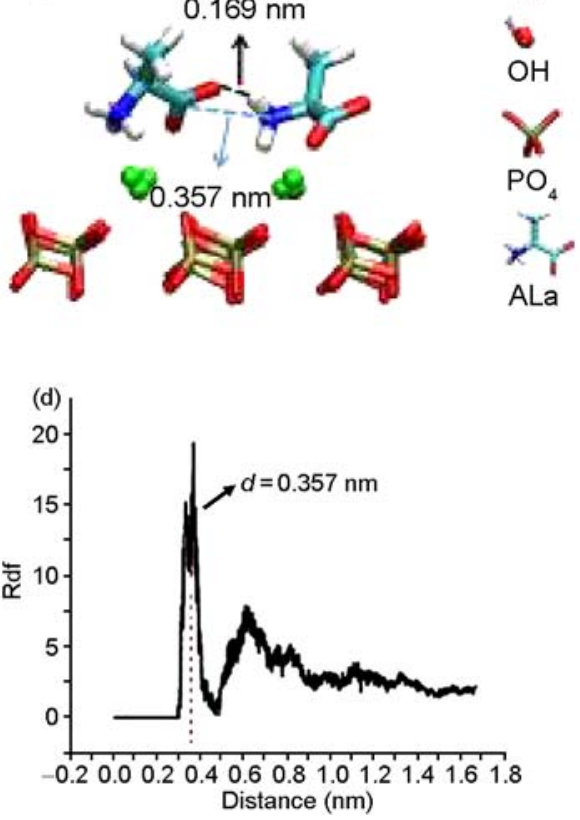

Figure 6 (a) Overhead view of the adsorption pattern of Ala on HAP $\{100\}$ facets. (b) Image at higher magnification revealing the interaction between neighboring Ala molecules marked by the green oval in (a). (c) Rdf of an $\mathrm{H}$ atom in an amino group around an $\mathrm{O}$ atom in the carboxyl group on the neighboring molecule. (d) Rdf of the $\mathrm{N}$ atom in an amino group around the $\mathrm{C}$ atom in the carboxyl group on the neighboring molecule. 

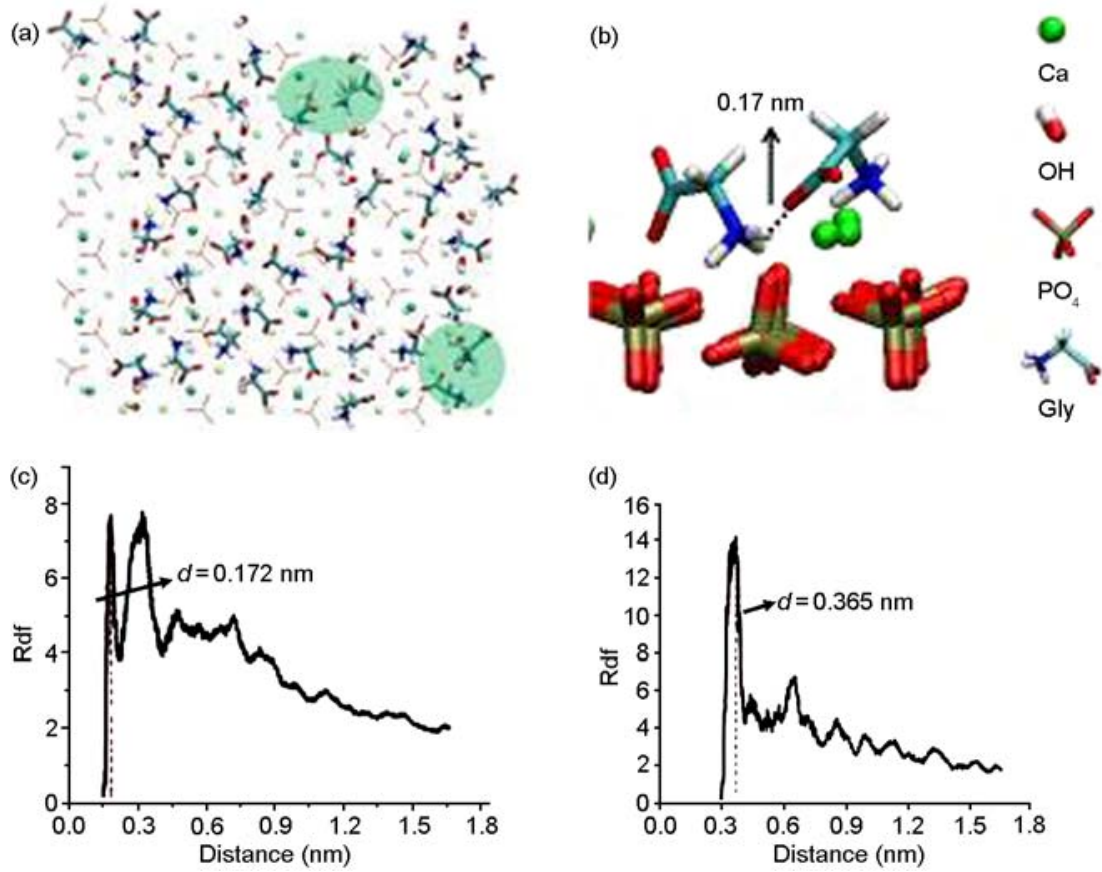

Figure 7 (a) Overhead view of Gly adsorption pattern on HAP $\{100\}$ facets. (b) Magnified views showing interactions between neighboring Gly molecules that are marked by green shadows in (a). (c) Rdf of an $\mathrm{H}$ atom in the amino groups around an $\mathrm{O}$ atom in the carboxyl group on the neighboring molecule. (d) Rdf of the $\mathrm{N}$ atom in an amino group around the $\mathrm{C}$ in the carboxyl group on the neighboring Gly molecule.

formation of dipetides does not require the harsh reaction conditions such as high temperature or high pressure that were essential for the continued chemical evolution of biomolecules over the long geological ages.

This work was supported by the National Natural Science Foundation of China (20601023 and 20871102), Zhejiang Provincial Natural Science Foundation (R407087), the Fundamental Research Funds for the Central Universities and Daming Biomineralization Foundation.

1 Eigen M. Molecular self organisation and evolution. Naturwissenschaften, 1971, 58: 465-523

2 Matsuno K. Natural self-organization of polynucleotides and polypeptides in protobiogenesis: Appearance of a protohypercycle. BioSystems, 1982, 15: 1-11

3 Kauffman S A. Autocatalytic sets of proteins. J Theor Biol, 1986, 119: 1-24

4 Orgel L E. Mini review: RNA catalysis and the origins of life. Ibid, 1986, 123: 127-149

5 Bada J L, Lazcano A. Some like it hot, but not the first biomolecules. Science, 2002, 296: 1982-1983

6 Brack A. From interstellar amino acids to prebiotic catalytic peptides: A review. Chem Biodiv, 2007, 4: 665-679

7 Schoonen M, Smirnov A, Cohn C. A perspective on the role of minerals in prebiotic synthesis. Ambio, 2004, 33: 539-551

8 Lahav N. Minerals and the origin of life - hypotheses and experiments in heterogeneous chemistry. Heterogen Chem Rev, 1994, 1: 159-179

9 Joshi P C, Pitsch S, Ferris J P. Homochiral selection in the montmorillonite-catalyzed and uncatalyzed prebiotic synthesis of RNA. Chem Commun, 2000: 2497-2498

10 Bujdák J, Eder A, Yongyai Y, et al. Investigation on the mechanism of peptide chain prolongation on montmorillonite. J Inorg Biochem, 1996, 61: 69-78
11 Bujdák J, Son H L, Rode B M. Montmorillonite catalyzed peptide bond formation: The effect of exchangeable cations. J Inorg Biochem, 1996, 63: 119-124

12 Basiuk V A, Gromovoy T Y, Golovaty V G, et al. Mechanisms of amino acid polycondensation on silica and alumina surfaces. Orig Life Evol Biosphere, 1990, 20: 483-498

13 Ferris J P, Hill A R Jr, Liu R H, et al. Synthesis of long prebiotic oligomers on mineral surfaces. Nature, 1996, 381: 59-61

14 Imai $\mathrm{E}$, Honda $\mathrm{H}$, Hatori $\mathrm{K}$, et al. Elongation of oligopeptides in a simulated submarine hydrothermal system. Science, 1999, 283: 831-833

15 Dorozhkin S V, Epple M. Biological and medical significance of calcium phosphates. Angew Chem Int Ed, 2002, 41: 3130-3146

16 Koutsopoulos S, Dalas E. Inhibition of hydroxyapatite formation in aqueous solutions by amino acids with hydrophobic side groups. Langmuir, 2000, 16: 6739-6744

17 Pan H, Tao J, Xu X, et al. Adsorption processes of gly and glu amino acids on hydroxyapatite surfaces at the atomic level. Langmuir, 2007, 23: 8972-8981

18 Tanaka H, Miyajima K, Nakagaki M, et al. Interactions of aspartic acid, alanine and lysine with hydroxyapatite. Chem Pharmac Bull, 1989, 37: 2897-2901

19 Churchill H, Teng H, Hazen R M. Correlation of pH-dependent surface interaction forces to amino acid adsorption: Implications for the origin of life. Am Mineral, 2004, 89: 1048-1055

20 Fujisawa R, Wada Y, Nodasaka Y, et al. Acidic amino acid-rich sequences as binding sites of osteonectin to hydroxyapatite crystals. Biochim Biophys Acta, 1996, 1292: 53-60

21 Hill A R Jr, Böhler C, Orgel L E. Polymerization on the rocks: Negatively - charged $\alpha$-amino acids. Orig Life Evol Biosphere, 1998, 28: 235-243

22 Capriotti L A, Beebe T P Jr, Schneider J P. Hydroxyapatite surfaceinduced peptide folding. J Am Chem Soc, 2007, 129: 5281-5287

23 Kafarov V. Cybernetic Methods in Chemistry and Chemical Engineering. Moscow: Mir Pub, 1976.

24 Kawamura K, Nishi T, Sakiyama T. Consecutive elongation of alanine oligopeptides at the second time range under hydrothermal conditions using a microflow reactor system. J Am Chem Soc, 2005, 127: 
$522-523$

25 Ferris J P. Chemical markers of prebiotic chemistry in hydrothermal systems. Orig Life Evol Biosphere, 1992, 22: 109-134

26 Amend J P, Shock E L. Energetics of amino acid synthesis in hydrothermal ecosystems. Science, 1998, 281: 1659-1662

27 Lahav N, White D, Chang S. Peptide formation in the prebiotic era: Thermal condensation of glycine in fluctuating clay environments. Science, 1978, 201: 67-69

28 Saetia S, Liedl K R, Eder A H, et al. Evaporation cycle experiments - a simulation of salt-induced peptide synthesis under possible prebiotic conditions. Orig Life Evol Biosphere, 1993, 23: 167-176

29 Rode B M, Son H L, Suwannachot Y. The combination of salt induced peptide formation reaction and clay catalysis: A way to higher peptides under primitive earth conditions. Orig Life Evol Biosphere, 1999, 29: 273-286

30 Hauptmann S, Dufner H, Brickmann J, et al. Potential energy function for apatites. Phys Chem Chem Phys, 2003, 5: 635-639

31 Berendsen H, van der Spoel D, van Drunen R. Gromacs: A messagepassing parallel molecular dynamics implementation. Comp Phys Commun, 1995, 91: 43-56

32 Lindahl E, Hess B, van der Spoel D. Gromacs 3.0: A package for molecular simulation and trajectory analysis. J Mol Model, 2001, 7: 306-317
33 Frenkel D, Smit B. Understanding Molecular Simulations. San Diego: Academic Press, 1996

34 Orgel L E. The origin of polynucleotide-directed protein synthesis. J Mol Evol, 1989, 29: 465-474

35 Rode B M, Schwendinger M G. Copper-catalyzed amino acid condensation in water - a simple possible way of prebiotic peptide formation. Orig Life Evol Biosphere, 1990, 20: 401-410

36 Nagayama M, Takaoka O, Inomata K, et al. Diketopiperazine-mediated peptide formation in aqueous solution. Orig Life Evol Biosphere, 1990, 20: 249-257

37 Cox J S, Seward T M. The reaction kinetics of alanine and glycine under hydrothermal conditions. Geochim Cosmochim Acta, 2007, 71: 2264-2284

38 Rode B M, Eder A H, Yongyai Y. Amino acid sequence preferences of the salt-induced peptide formation reaction in comparison to archaic cell protein composition. Inorg Chim Acta, 1997, 254: 309-314

39 Rimola A, Sodupe M, Ugliengo P. Aluminosilicate surfaces as promoters for peptide bond formation: An assessment of bernal's hypothesis by $a b$ initio methods. J Am Chem Soc, 2007, 129: 8333-8344

40 Rimola A, Tosoni S, Sodupe M, et al. Does silica surface catalyze peptide bond formation? New insights from first-principles calculations. Chem Phys Chem, 2006, 7: 157-163 